\title{
EDITORIAL
}

\section{JSE's First Retraction}

\section{Stephen E. Braude}

https://doi.org/10.31275/20202077

Creative Commons License CC-BY-NC

T

his issue of the JSE includes a retraction of a paper by Alejandro Parra we published in 2017. As far as I can determine, it's the journal's first official retraction of a published paper. The reason for this action is the author's extensive plagiarism, both in that paper and in other published work

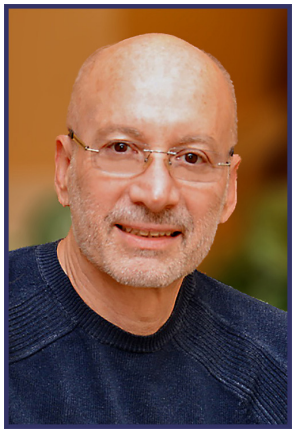
(including a recent book whose publisher has since recalled all copies). It's a sad state of affairs, of course-and perhaps the first of its kind in this particular and admittedly minor scientific domain.

It reminds me that six years ago, in Volume 29(2), we published a paper on retractions in science, and in that issue I seized the opportunity to editorialize further on the subject. I recycle that Editorial below. But before that, I must note that careful examination has found no evidence of plagiarism in the one other research article (in 2018) and the one book review we've published by Parra-however, a recent Parra submission to JSE (that we rejected) was substantially plagiarized, except for an added abstract, from a paper published in Spanish by another author in another journal. I must also mention that, henceforth, the JSE will run routine plagiarism tests on papers accepted for publication. I thought this was a chore l'd left behind when I retired from teaching. However, I don't want the JSE to emulate the person who said "I've learned from my mistakes, and I'm certain I can repeat them exactly."

EDITORIAL from JSE Volume 29(2) in 2015, pp. 189-194

ne of the Commentaries in this issue is something of a departure for the JSE. The paper by Jaime A. Teixeira da Silva (https://www.scientificexploration.org/docs/29/jse_29_2_TeixeiradaSilva.pdf) 
concerns retractions in scientific publications, a topic that has been receiving increasing attention in recent years, apparently coinciding with an increasing number of retractions over the same period. Because the SSE and JSE focus not only on specific (usually controversial or neglected) domains of scientific investigation but also on broader issues concerning the practice of science itself, I figured that the cluster of issues surrounding retractions might be of both theoretical and practical interest to JSE readers.

The sheer number of retractions is enough to give one pause. A recent survey by R. Grant Steen of the PubMed database from 2000 to 2010 identified 788 retracted papers (Steen, 2011). For 46 of those papers, Steen was unable to find formal retraction notices. So, his survey dealt with the remaining 742 papers for which he could obtain such notices. The reasons for retraction were broadly identified as fraud and error. The former included data fabrication and data falsification, and the latter included (among other things) plagiarism, ${ }^{1}$ scientific mistake, and ethical issues (violations of accepted publication practices-for example, IRB [Institutional Review Board] violations). Steen found that the reason for retraction was more often error than fraud- $73.5 \%$ as compared to $26.5 \%$.

A later survey (Steen et al., 2013) examined the interval between publication and retraction for what strikes me as an astounding 2,047 retracted articles indexed in PubMed. ${ }^{2}$ And the number of papers that should be retracted may well be greater than that. As Cokol et al. (2007) observe, "Retracting a published scientific article is the academic counterpart of recalling a flawed industrial product" (p. 422). But

... articles published in more prominent scientific journals receive increased attention and a concomitant increase in the level of scrutiny. This therefore raises the question of how many articles would have to be retracted if the highest standards of screening were universally applied to all journals. (Cokol et al., 2007)

Moreover, as Vedran Katavić noted, "the retracted articles do not die, but rather receive citations years and decades after their retraction, often by the authors themselves" (Katavić, 2014, p. 217). So one can easily see why da Silva is concerned about the consequences of all these 
retractions for the downstream scientific literature. Katavić, in fact, supplies a stunning example of the extent to which retracted articles can infiltrate and leave traces in the media.

On January 30, 2014, the scientific journal Nature published two papers by Haruko Obokata et al. detailing reprogramming of somatic into stem cells by an acidic bath. The journal's article metrics allow for some understanding of the impact these articles have attracted so far, before their inevitable retraction (at the time of writing this opinion piece, both papers are under investigation for fraud). Within approximately 50 days of publication, these two articles (taken together) have been tweeted about over 3,300 times, appeared on more than 100 Facebook pages, picked up by 130 news outlets, cited a total of 30 times (which puts them above the goth percentile of tracked articles of similar age across journals or in Nature), blogged about on at least 50 scientific blogs, and their web pages at the source through the nature.com journal platform have been viewed (HTML views and PDF downloads) more than 1,300,000 times total! (Katavić, 2014, pp. 220-221)

Another piece of information I found especially startling was a presumably incomplete list of scientists with multiple retractions, some of them with truly amazing totals. Consider Table 1, provided by Katavić (2014, p. 219).

In addition to the specific concerns raised by da Silva, my own brief search of the relevant literature turned up the intriguing finding that "the probability that an article published in a higher-impact journal will be retracted is higher than that for an article published in a lowerimpact journal" (Fang \& Casadevall, 2011, p. 3856). The authors write,

The correlation between a journal's retraction index and its impact factor suggests that there may be systemic aspects of the scientific publication process that can affect the likelihood of retraction. When considering various explanations, it is important to note that the economics and sociology of the current scientific enterprise dictate that publication in high-impact journals can confer a disproportionate benefit to authors relative to publication of the same material in a journal with a lower impact factor. For example, publication in journals with high impact factors can be associated with improved job opportunities, grant success, peer recognition, 
TABLE 1

Some Authors with Multiple Retractions from the Last Decade

\begin{tabular}{|c|c|c|}
\hline Name & Scientific field & $\begin{array}{c}\text { Number of retracted } \\
\text { publications }\end{array}$ \\
\hline Yoshitaka Fujii & Anesthesiology & 170 \\
\hline Joachim Boldt & Anesthesiology & 90 \\
\hline $\begin{array}{l}\text { Friedhelm Herrmann / } \\
\text { Marion Brach }\end{array}$ & Neuroscience & 94 \\
\hline Diderik Stapel & Psychology & 50 \\
\hline Naoki Mori & Immunology & 30 \\
\hline Jan Hendrik Schön & Physics & 25 \\
\hline Shigeaki Kato & Biomedicine & 20 \\
\hline Alirio Melendez & Immunology & 20 \\
\hline Dipak K. Das (late) & Biomedicine & 20 \\
\hline Silvia Bulfone-Paus & Biomedicine & 13 \\
\hline Eric Poehlman & Biomedicine & 10 \\
\hline Bengü Sezen & Biochemistry & 9 \\
\hline Dirk Smeesters & Psychology & 7 \\
\hline
\end{tabular}

Source: Reprinted from Table 1 in Katavić, V. (2014). Retractions of scientific publications: Responsibility and accountability. Biochemia Medica (Zagreb), 24(2), 217-222.

https://www.biochemia-medica.com/en/journal/24/2/10.11613/BM.2014.024/fullArticle

and honorific rewards, despite widespread acknowledgment that impact factor is a flawed measure of scientific quality and importance. ... Hence, one possibility is that fraud and scientific misconduct are higher in papers submitted and accepted to higher-impact journals. In this regard, the disproportionally high payoff associated with publishing in higher-impact journals could encourage risk-taking behavior by authors in study design, data presentation, data analysis, and interpretation that subsequently leads to the retraction of the work. Another possibility is that the desire of high-impact journals for clear and definitive reports may encourage authors to manipulate their data to meet this expectation. In contradistinction to the crisp, orderly results of a typical 
manuscript in a high-impact journal, the reality of everyday science is often a messy affair littered with nonreproducible experiments, outlier data points, unexplained results, and observations that fail to fit into a neat story. In such situations, desperate authors may be enticed to take short cuts, withhold data from the review process, over-interpret results, manipulate images, and engage in behavior ranging from questionable practices to outright fraud. . . . Alternatively, publications in high-impact journals have increased visibility and may accordingly attract greater scrutiny that results in the discovery of problems eventually leading to retraction. It is possible that each of these explanations contributes to the correlation between retraction index and impact factor. Whatever the explanation, the phenomenon appears deserving of further study. The relationship between retraction index and impact factor is yet another reason to be wary of simple bibliometric measures of scientific performance, such as impact factor. ${ }^{3}$ (Fang \& Casadevall, 2011, pp. 3856-3857)

Furthermore, according to Shi V. Liu, the high impact factor (IF)

for some journals is actually based—at least in part-on the high number of citations of their retracted papers. . . . Rather than removing these 'negative contributions' from the IF calculation, these journals have continued to use their inflated IFs to promote their publications. (Liu, 2007, p. 792)

I should add that, among the many interesting observations in the passage quoted above from Fang and Casadevall, I found it refreshing to see the authors acknowledge that "the reality of everyday science is often a messy affair littered with nonreproducible experiments, outlier data points, unexplained results, and observations that fail to fit into a neat story." No doubt JSE readers (and authors) are all too aware of this, although that grubby reality is often ignored by critics of the research to which this Journal is devoted. (Katavić also has some pertinent observations on this topic.)

Because I felt that this general topic of retractions would be of considerable interest to JSE readers, I thought I might be able to stimulate commentaries on the Commentary by reaching out to various SSE stalwarts and some others, to see if they wanted to offer reflections of their own. Here are some of those responses: Their authors have 
allowed me to submit them for your further consideration. From psychiatrist and psychoanalyst (and dissociation researcher) John O'Neil (personal communication, February 3, 2015):

With increasing digitization, there's more and more automatic registering of what gets cited, so I assume that at some point in the future there may be some automatic tag that goes on all papers citing a retracted paper, and then some derivative tag that goes on all papers citing a paper that cites a retracted paper, etc. Though at that point the carbon-based units would need to take over for a little interpretation.

Automatic tagging wouldn't suffice, of course, as a review paper might cite a retracted paper as an example of a retracted paper, and cite the retraction as well, I would assume, so then there would need to be some mechanism to have the 'tag' removed from that paper; otherwise the tag would mislead, and be carried into all the 'progeny' of the paper concerned. So the idea that a retraction [can] cause the retracted paper to cease to exist is nonsense. What happens instead is a published retraction by an author (or publisher), and this compromises the credibility of the paper.

And then, of course, there's the forced retraction. Like Galileo (or whoever) retracting solid science under social, political, or religious pressure. So a retraction may be done to save one's skin. Or to please others (e.g., retractions of accusations of incestuous sexual abuse). So, retractions arising from a lack of moral fibre (to use some dated expression).

So I think the author is onto an important point, but I also think the devil is in the details.

From my editorial predecessor, Henry Bauer, some characteristically trenchant comments (February 14, 2015):

That retracted material continues to be cited and the retraction known is unquestionably a bad thing. However, it is whistling in the wind to call for systemic solutions: There is no mechanism by which solutions could be enforced.

The problem arises in part from "publish or perish," nowadays more aptly "get grants continually or perish." That has led to a spate of online commercial publishers putting out hordes of journals whose only purpose is to allow grant-seekers to publish anything at all merely by paying "publication costs" (more at "Fake, 
deceptive, predatory Science Journals and Conferences," http:// wp.me/p2VG42-29).

If researchers were to be more scrupulous in checking what they cite, and peer reviewers were more conscientious, and editors, too, then the problem would not have reached its present proportions. That is water under the bridge. The issue da Silva addresses is simply one aspect of how science has become corrupted through excessive expectations and expansion, see "The Science Bubble" in EdgeScience \#17, February 2014, http://www.scientificexploration. org/edgescience/17

Of greater concern to me and others who try to get minority views published is retraction as a form of censorship, the retraction of articles that had been accepted after appropriate review but whose publication meets storms of protest from vigilante defenders of mainstream orthodoxy. See, for example, the story of the demise of the journal Medical Hypotheses for transgressing HIV/AIDS theory, Chapter 3 in my Dogmatism in Science and Medicine (McFarland 2012). More recently a literature review of the controversy over HIV/AIDS by Patricia Goodson survived the call for retraction with the editors compromising by changing it to an "Opinion" piece from the original "Hypothesis and Theory," though apparently its abstract has been removed from PubMed (article and comments at http://journal.frontiersin.org/Journal/10.3389/fpubh.2014.00154/ full; protest is at http://journal.frontiersin.org/Journal/10.3389/ fpubh.2015.00030/full; and publisher's statement at http://journal. frontiersin.org/Journal/10.3389/fpubh.2015.00037/full).

Finally, Michael Ibison (personal communication, February 14, 2015) contributed this:

I wonder if in the future the 'static' paper will be a special case, the more common being a dynamic version subject to continuous revision. The latter is already under way at arXiv and ResearchGate. For this reason, when I have an interest in a recent journal paper I check out arXiv and elsewhere on the Web, sometimes finding a 'new and improved' and/or extended version. The journal paper might function as an 'advertisement' in such cases.

I have no particular ax to grind (yet) with respect to this general topic of retractions and their aftermath. However, I look forward to seeing whether SSE members want to pursue the topic further, either 
with commentaries or correspondence submitted to the JSE, or perhaps at one of our conferences.

\section{NOTES}

One might wonder why plagiarism isn't considered fraud.

2 See also the figures cited recently by Gasparyan et al. (2014).

3 For further commentary, see, e.g., Cokol et al. (2007), Gasparyan et al. (2014), Gewin (2014), Katavić (2014), Liu (2007), Steen (2011), and Steen et al. (2013).

\section{REFERENCES}

Cokol, M., lossifov, I., Rodriguez-Esteban, R., \& Rzhetsky, A. (2007). How many scientific papers should be retracted? EMBO Reports, 8(5), 422-423. https:// doi.org/10.1038/sj.embor.7400970

Fang, F. C., \& Casadevall, A. (2011). Editorial: Retracted science and the retraction index. Infection and Immunity, 79(10), 3855-3859.

https://iai.asm.org/content/79/10/3855.short

Gasparyan, A. Y., Ayvazyan, L., Akazhanov, N. A., \& Kitas, G. D. (2014). Self-correction in biomedical publications and the scientific impact. Croatian Medical Journal, 55(1), 61-72.

https://www.ncbi.nlm.nih.gov/pmc/articles/PMC3944419/

Gewin, V. (2014). Retractions: A clean slate. Nature, 507, 389-391. https://www.nature.com/articles/nj7492-389a

Katavić, V. (2014). Retractions of scientific publications: Responsibility and accountability. Biochemia Medica (Zagreb), 24(2), 217-222.

https://www.biochemia-medica.com/en/journal/24/2/10.11613/BM.2014.024

Liu, S. V. (2007). Comment on the correspondence by Cokol et al. EMBO Reports, 8(9), 792-793.

Steen, R. G. (2011). Retractions in the scientific literature: Is the incidence of research fraud increasing? Journal of Medical Ethics, 37, 249-253. https://jme.bmj.com/content/37/4/249

Steen, R. G., Casadevall, A., \& Fang, F. C. (2013). Why has the number of scientific retractions increased? PLoS One, 8(7), e68397.

https://journals.plos.org/plosone/article?id=10.1371/journal.pone.0068397 